\title{
ANALISIS KINERJA SIMPANG TIGA SRIWEDARI MENGGUNAKAN PROGRAM SIMULASI PTV VISSIM
}

\author{
Sonia Aprilya ${ }^{1)}$, Budi Yulianto ${ }^{2)}$, Setiono ${ }^{3)}$ \\ 1) Mahasiswa Fakultas Teknik, Prodi Teknik Sipil, Universitas Sebelas Maret \\ 2), 3) Pengajar Fakultas Teknik, Prodi Teknik Sipil, Universitas Sebelas Maret \\ J1. Ir. Sutami No. 36A, Kentingan, Surakarta 57126, Telp. (0271) 647069, Fax 634524 \\ Email : sonia.aprilya@student.uns.ac.id
}

\begin{abstract}
The increasing number of the private vebicle ownership often causes trafficjams on the numerous public roads, especially in Surakarta. In order to anticipate this kind of obstacle, Surakarta revitalized the regular city public transport into Rapid Transport Bus or BRT (Bus Rapid Transit), which is called BST (Batik. Solo Trans). On September 1st, 2010, BST with corridor number 1 started operating from Adi Soemarmo Airport to Palur and vice versa, going through Brigien Slamet Riyadistreet. Besides, to gain an easy accessfor corridor 1, the Contraflow Bus Lane is needed on Brigjen Slamet Riyadi street. Accordingly, the additional control on the five-lane on the main street of Brigjen Slamet Riyadi is also necessary, especially on the signalized intersection in Sriwedari, which is the signaled cross road that uses Fixed Time Controller system in operating the traffic. This research aimed at modeling and analyzing the work of the signalized intersection in Sriwedari that uses FTC, Signal Optimization scenario, and the increase of Pedestrian Phase, which uses PTV VISSIM simulation program. The calibration and validation process were done on the basic model only to obtain more accurate data. In the calibration process, the Geoffrey E. Havers (GEH) statistics test was conducted towards the trafficflow on each side of the cross roads to acknowledge whether it s model had been calibrated ornot. Meanwhile, on the validation process, the researcher used T test towards the maximum queue length on every 10 (ten) minutes and the difference test towards the $L V$ travel time to understand whether the data had been calibrated. As the results, this research can be concluded that Signal Optimization system affected significantly forthe increase of the function of signaled intersection of Sriwedariespecially that can be seen from the delay and the length of the traffic queue.
\end{abstract}

Keywords: GEH, PTV VISSIM, Sriwedari

\begin{abstract}
Abstrak
Meningkatnyajumlah kepemilikan kendaraan pribadi menyebabkan meningkatnya tingkatkemacetan pada sejumlah ruas jalan, khususnya di Kota Surakarta. Untuk mengantisipasi hal tersebut, Pemerintah Kota (Pemkot) Surakarta merevitalisasi angkutan umum perkotaan reguler menjadi angkutan umum yang berbasis Bus Rapid Transit yaitu Batik Solo Trans (BST). Pada tanggal 1 September 2020 BST Koridor 1 mulai dioperasikan via Jalan Brigjen Slamet Riyadi. Untuk memudahkan akses BST Koridor 1, perlu adanya sistem Contraflow BusLane pada ruas Jalan Brigjen Slamet Riyadi. Sehubungan dengan hal tersebut, perlu diadakan pengendalian pada kelima simpang utama jalan Brigjen Slamet Riyadi, salah satunya pada Simpang Bersinyal Sriwedari, yang merupakan simpang tiga bersinyal yang menggunakan sistem fixed time controller dalam pengoperasian lalu lintasnya. Penelitian ini bertujuan untuk memodelkan dan menganalisis kinerja Simpang Bersinyal Sriwedari dengan sistem Fixed Time Controller menggunakan program PTV VISSIM. Proses kalibrasi dan validasi dilakukan pada base model agar mendapatkan hasil yang akurat dan mendekati kenyataan. Pada proses kalibrasi dilakukan uji statistic Geoffrey E. Havers (GEH) terhadap arus lalu lintas di lenganlengan simpang untuk mengetahui apakah model telah terkalibrasi. Sedangkan pada proses validasi dilakukan uji t terhadap panjang antrian maksimum tiap interval 10 menit dan uji perbedaan relatif terhadap waktu perjalanan LV untuk mengetahui apakah model telah tervalidasi.
\end{abstract}

Kata Kunci : GEH, PTV VISSIM, Sriwedari

\section{PENDAHULUAN}

Dalam mengantisipasi permasalahan lalu lintas di Kota Surakarta, maka Pemerintah Kota Surakarta mencanangkan visi Kota Surakarta menuju kota dengan transportasi yang berkelanjutan atau sustainable transportation (Dishubkominfo Kota Surakarta, 2016). Salah satu program kerja Pemerintah Kota Surakarta merevitalisasi angkutan umum perkotaan menjadi berbasis Bus Rapid Transit (BRT) yaitu Batik Solo Trans (BST). Saat ini Kota Surakarta telah menerapkan Jalur Contraflow Bus Lanes untuk Bus Batik Solo Trans (BST) Koridor Satu disepanjang Jalan Brigjen Slamet Riyadi guna mengoptimalkan fasilitas layanan publik transportasi umum ini dikarenakan sebelumnya BST Koridor 1 hanya satu arah sehingga penumpang harus memutar melalui Jalan Veteran. Kini Batik Solo Trans (BST) Koridor 1 telah memiliki rute dengan destinasi Bandara Adi Soemarmo - Palur yang melewati Jl. Brigjen Slamet Riyadi dengan jalur khusus BST (Contra-Flow Bus Lanes) dan destinasiTerminal Palur-Bandara Adi Sumarmo. Dengan adanya kebijakan ini diharapkan dapat meningkatkan minat masyarakat menggunakan transportasi umum. Langkah tersebut merupakan langkah untuk terciptanya sistem transportasi berkelanjutan di Kota Surakarta. Namun adanyalajur khusus contraflowbus 
lanes ini juga membuat adanya perubahan rekayasa lalu lintas di sepanjang Jalan Brigjen Slamet Riyadi termasuk Simpang Bersinyal Sriwedari. Maka dari itu diperlukan pengendalian pengaturan lalu lintas di sepanjang Jalan Brigjen Slamet Riyadi khususnya pada simpang - simpang.

Simpang merupakan area konflik arus lalu lintas yang rawan akan kemacetan, karena merupakan bertemunya dua ruas jalan atau lebih (Pignataro, 1973). Simpang dibagi menjadi empat jenis berdasarkan pola pergerakannya, yaitu berpotongan, bergabung, berpisah, dan berjalinan. Kemudian menurut tingkat arus lalu lintasnya, simpang dibagi menjadi simpang tanpa prioritas, simpang dengan prioritas, simpang dengan bundaran, simpang dengan lampu lalu lintas, dan yang terakhir simpang tak sebidang. Kemampuan kinerja simpang dinilai dari beberapa faktor, yaitu tingkat pelayanan, kapasitas, derajat kejenuhan, tundaan, panjang antrian, waktu siklus, arus lalu lintas, hambatan samping, dan kecepatan.

Penelitian ini dilakukan di Simpang Tiga Bersinyal Sriwedari dengan simpang steger di sisi utara. Simpang Sriwedari terletak di Kecamatan Laweyan dimana lokasi tersebut merupakan kawasan strategis dengan akses transportasi yang mudah, dan kawasan sekitarnya merupakan kawasan pembangunan yang aktif seperti Stadion Sriwedari, Grand Mall Solo, Mall dan Apartemen Solo Paragon, dan taman hiburan Sriwedari sendiri yang sering dikunjungi masyarakat Surakarta. Simpang Sriwedari memiliki kaki simpang disisi selatannya Jalan Bhayangkara, sisi barat dan timur yaitu Jl. Brigjen Slamet Riyadi dimana ketiganya memiliki arus lalu lintas yang tinggi. Kawasan Simpang Sriwedari juga memiliki jalur pedestrian dan jalur lambat yang lumayan luas dan sangat memadai bagi pengguna pejalan kaki maupun pesepeda. Dengan kondisi lalu lintas yang heterogen (mixed traffic) di simpang ini, perlu adanya kajian untuk mengetahui kinerja Simpang Sriwedari apakah sudah menunjang fasilitas transportasi berkelanjutan, dan untuk menganalisis kinerja simpang ini menggunakan program simulasi PTVVISSIM yang nantinya pemodelan simpang di VISSIM akan di validasi dan parameter lalu lintasnya akan dikalibrasi secara konsistenagardapatmenyamaidata dilapangan.

\section{METODE}

\section{Pengumpulan Data}

Dalam proses pembuatan model simulasi, diperlukan data yang digunakan sebagai input. Pada penelitian kali ini, penulis menggunakan dua jenis data yaitu data primer dan sekunder. Data primer merupakan data yang diperoleh melalui pelaksanaan survei langsung di lapangan, yang meliputi:

1. pencacahan lalu linta,

2. kecepatan kendaraan,

3. waktu perjalanan,

4. panjang antrian,

5. waktu siklus lampu lalu lintas, dan

6. geometri simpang dan ruas jalan.

Data sekunder adalah data yang diperoleh melalui studi literatur, atau media perantara lainnya. Pada penelitian kali ini, penulis menggunakan data sekunder berupa foto udara Google Maps yang dipergunakan sebagai latar belakang proses pemodelan pada PTV VISSIM.

\section{Program Simulasi PTV VISSIM}

Pada penelitian kali ini, digunakan program simulasi PTV VISSIM. Program ini merupakan mikrosimulasi yang memiliki kemampuan untuk melaksanakan analisa, perencanaan, serta optimalisasi kinerja lalu lintas.

\section{Kalibrasi dan Validasi PTV VISSIM}

Kalibrasi merupakan proses penyesuaian parameter yang dilakukan beberapa kali hingga nilai yang dihasilkan dari model simulasi sesuai dengan nilai yang didapatkan dari hasil penghitungan di lapangan. Pada penelitian kali ini jumlah arus lalu lintas setiap kaki simpang ditetapkan sebagai parameter. Kemudian untuk validasi sendiri merupakan tahapan yang dilakukan untuk mengetahui apakah model simulasilalu lintas dapat merepresentasikan keadaan lalu lintas realita atau tidak. Model simulasi dinyatakan valid apabila memenuhi persyaratan jika keluaran data model mendekati data observasi lapangan. Pada penelitian ini, waktu tempuh perjalanan atau travel time, dan panjang antrian kendaraan dijadikan sebagai variabel, serta dihitung menggunakan rumus: 
1. Perbedaan Relatif (Relative Difference)

Merupakan metode perhitungan yang dilakukan dengan cara membandingkan nilai perbedaan mutlak dengan nilai yang didapatkan dari hasil observasi lapangan. Sedangkan, nilai perbedaan mutlak sendiri merupakan hasil pengurangan dari nilai yang didapatkan dari model simulasi dengan nilai hasil observasi.

Perbedaan Relatif $=\frac{\text { Nilai Model }- \text { Nilai Obeservasi }}{\text { Nilai Observasi }}$.... [1]

\section{Statistik GEH (Gepffrey E. Havers)}

Merupakan rumus persamaan yang menentukan kesesuaian antara jumlah arus lalu lintas dengan membandingkan hasil survei observasi lapangan dengan model simulasi.

$$
G E H=\sqrt{\frac{\left(\mathrm{q}_{m}-q_{o}\right)^{2}}{0,5 \times\left(q_{m}+q_{o}\right)}}
$$

Dengan rincian

$\mathrm{q}_{\mathrm{m}}=$ arus lalu lintas Model

$\mathrm{q}_{\mathrm{o}} \quad=$ arus lalu lintas hasil Observasi

\section{Independent Sample T-Test}

Uji T-Test digunakan sebagai acuan untuk menentukan apakah dua sampel yang tidak sama memiliki rata rata yang berbeda. Uji T untuk varian yang sama (equal variance) menggunakan rumus Polled Varians:

$$
t=\frac{\bar{x}_{1}-\bar{x}_{2}}{s \sqrt{\frac{1}{n_{1}}}-\frac{1}{n_{2}}}
$$

Dengan:

$x_{1}=$ rata-rata data set pertama

$x_{2}=$ rata-rata data set kedua

$n_{1}=$ jumlah data pada kumpulan pertama

$n_{2}=$ jumlah data pada kumpulan kedua

$S=$ varian dengan rumus pada persamaan

Cara mengetahui signifikansi hasil uji $\mathrm{t}$ bisa dilihat dari perbandingan dari $\mathrm{t}_{\text {hitung }}$ dan $\mathrm{t}_{\text {tabel }}($ two tailed) dan hasil nilai $\mathrm{P}$ (two tailed). Apabila nilai thitung $<$ dari tabel (two tailed) dan hasil $\mathrm{P}$ (two tailed) $>0,05$, maka perbedaan yang dihasilkan diterima. 


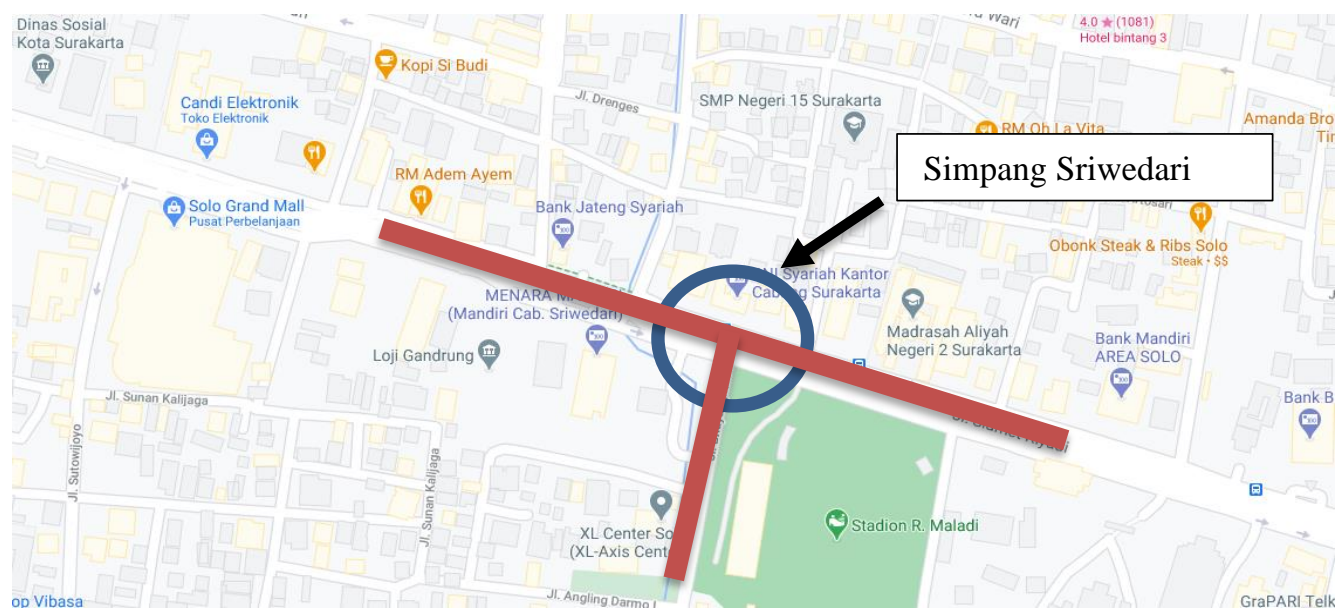

Gambar 1. Lokasi Penelitian (Sumber: Google Maps)

\section{Analisis Data}

Setelah menghasilkan model simulasi yang sesuai dengan data yang diperoleh, maka dilakukan analisis yang nantinya akan menghasilkan beberapa parameter, diantaranya yaitu panjang antrian, tundaa, serta waktu perjalanan.

\section{Kalibrasi dan Validasi Base Model}

Proses kalibrasi dan validasi menggunakan parameter yang sebelumnya telah pernah diujikan di beberapa penelitian, seperti Lateral behavior, Desired position of free flows, Default behavior when overtaking vebicle on the same lane, Following behavior, Average standstill distance yang terdapat dalam menu Driving behavior (Nurjannah, 2015)

\section{HASIL DAN PEMBAHASAN}

Untuk mengetahui apakah model simulasi dapat merepresentasikan keadaan eksisting atau tidak, maka dilakukan kalibrasi dengan menggunakan uji statistik GEH guna menghitung selisih jumlah arus lalu lintas model dengan hasil observasi setiap simpang.

Tabel 1. Hasil Uji GEH pada arus lalu lintas pada jam puncak

\begin{tabular}{|c|c|c|c|c|c|c|c|c|c|}
\hline \multirow{3}{*}{ Lokasi } & \multicolumn{6}{|c|}{$\mathrm{q}_{\mathrm{m}}$} & \multirow{3}{*}{ qo } & \multirow{3}{*}{$\begin{array}{l}\text { Nilai } \\
\text { GEH }\end{array}$} & \multirow{3}{*}{ Keterangan } \\
\hline & \multicolumn{5}{|c|}{ Run ke- } & \multirow{2}{*}{ Rata-rata } & & & \\
\hline & 1 & 2 & 3 & 4 & 5 & & & & \\
\hline 1 & 3956 & 4047 & 3950 & 3904 & 4007 & 3973 & 3935 & 0,60 & Diterima \\
\hline 2 & 1333 & 1432 & 1392 & 1321 & 1440 & 1384 & 1369 & 0,40 & Diterima \\
\hline 3 & 1366 & 1382 & 1329 & 1367 & 1349 & 1359 & 1364 & 0,14 & Diterima \\
\hline 4 & 3752 & 3917 & 3840 & 3658 & 3914 & 3816 & 3948 & 2,12 & Diterima \\
\hline
\end{tabular}

Berdasarkan hasil analisis menggunakan rumus statistic GEH dapat disimpulkan jika model simulasi dapat merepresentasikan keadaan lalu lintas yang sesungguhnya di lapangan. Setelah dilakukan kalibrasi, maka tahap selanjutnya adalah melakukan tahap validasi menggunakan uji paired sample ttest pada data panjang antrian maksimum setiap simpang dengan interval waktu 10 menit, dan waktu tempuh perjalanan. 
Tabel 2. Hasil uji T-test panjang antrian pada jam puncak

\begin{tabular}{|c|c|c|c|c|c|c|c|c|}
\hline \multirow{2}{*}{ No. } & \multirow{2}{*}{$\begin{array}{l}\text { Lengan } \\
\text { Simpang }\end{array}$} & \multirow{2}{*}{$\begin{array}{l}\text { Interval } \\
\text { menit ke }\end{array}$} & \multicolumn{2}{|c|}{$\begin{array}{l}\text { Panjang Antrian } \\
\text { Maksimum (m) }\end{array}$} & \multirow{2}{*}{$\mathbf{t}$ hitung } & \multirow{2}{*}{$\mathbf{t}$ tabel } & \multirow{2}{*}{$\mathbf{P}$} & \multirow{2}{*}{ Keterangan } \\
\hline & & & Model & Observasi & & & & \\
\hline & Selatan & 16:10:06 & 46 & 55 & $-3,037$ & 2.228 & 0.013 & Diterima \\
\hline & & $16: 20: 06$ & 56 & 58 & & & & \\
\hline & & 16:30:06 & 49 & 54 & & & & \\
\hline & & 16:40:06 & 50 & 52 & & & & \\
\hline & & 16:50:06 & 49 & 53 & & & & \\
\hline & & 17:00:06 & 49 & 58 & & & & \\
\hline \multirow[t]{6}{*}{2} & Barat & $16: 10: 50$ & 132 & 139 & -0.597 & 2.228 & 0.564 & Diterima \\
\hline & & $16: 20: 50$ & 149 & 145 & & & & \\
\hline & & $16: 30: 50$ & 140 & 140 & & & & \\
\hline & & $16: 40: 50$ & 161 & 132 & & & & \\
\hline & & $16: 50: 50$ & 131 & 155 & & & & \\
\hline & & $17: 00: 50$ & 135 & 160 & & & & \\
\hline
\end{tabular}

Berdasarkan Tabel 1 dan Tabel 2 hasil uji keduanya memiliki nilai P lebih besar dari 0,05, dan nilai tabel yang lebih besar dari thitung yang berarti panjang antrian pada model simulasi dapat merepresentasikan keadaan panjang antrian pada kondisi eksisting. Selanjutnya dilakukan uji validasi pada waktu tempuh perjalanan atau Travel Time menggunakan uji perbedaan relatif.

Tabel 3. Hasil validasi waktu perjalanan sore

\begin{tabular}{|c|c|c|c|c|c|}
\hline \multirow[t]{2}{*}{ No. } & \multirow[t]{2}{*}{$\begin{array}{r}\text { Asal-Tujuan } \\
\text { Perjalanan }\end{array}$} & \multicolumn{2}{|c|}{$\begin{array}{c}\text { Waktu Perjalanan Rata- } \\
\text { rata (detik) }\end{array}$} & \multirow[t]{2}{*}{$\begin{array}{c}\text { Persentase } \\
\text { PerbedaanRelatif }\end{array}$} & \multirow[t]{2}{*}{ Keterangan } \\
\hline & & Model & Observasi & & \\
\hline 1 & Barat-Timur & 141 & 132 & $7 \%$ & Diterima \\
\hline
\end{tabular}

Berdasarkan nilai yang didapatkan dari hasil uji relatif pada Tabel 3, didapatkan hasil dengan nilai kurang dari sama dengan 15\%, sehingga dapat disimpulkan jika waktu tempuh pada model simulasi dan kondisi eksisting memiliki rata-rata yang sebanding atau tidak memiliki perbedaan nilai yang signifikan.

\section{SIMPULAN}

Base model Simpang Sriwedari kondisi eksisting sudah dikalibrasi yang dibuktikan dengan hasil kalibrasi menggunakan nilai GEH kurang dari 5 , dan divalidasi dengan hasil uji $t$ pada panjang antrian maksimum menunjukan nilai $\mathrm{t}_{\text {hitung }}$ lebih kecil dari $\mathrm{t}_{\text {tabel }}\left(\mathrm{t}_{\text {hitung }}<\mathrm{t}_{\text {tabel }}\right)$ dan $\mathrm{P}_{(\text {two-tailed })}>0,05$ sehingga panjang antrian maksimum hasil output model dan observasi tidak terdapat perbedaan yang signifikan, serta uji kesesuaian parameter waktu perjalanan diterima dengan nilai 7\% lebih kecil dari 15\%. Pada kinerja pemodelan eksisting menunjukan panjang antrian sebesar 15 meter dan 37 meter pada kondisi jam puncak pagi dan sore, waktu perjalanan 116 detik dan 126 detik pada kondisi jam puncak pagi dan sore, tundaan 27 meter dan 41 meter pada kondisi jam puncak pagi dan sore. Dari hasil analisis berupa proses kalibrasi dan validasi, dapat disimpulkan bahwa model dari Simpang Bersinyal Sriwedari yang telah dibuat dinyatakan valid, dengan hasil output model mendekati hasil observasi sesuai dengan syarat - syarat dari tiap pengujian yang dilaksanakan.

\section{UCAPAN TERIMAKASIH}

Penulis mengucapkan puji syukur dan terima kasih kepada Tuhan Yang Maha Esa, serta segenap pihak yang mendukung terselesaikannya, dan diterbitkannya penelitian ini.

\section{REFERENSI}

Diskominfo Kota Surakarta, 2020, "Visi dan Misi Kota Surakarta 2016 - 2021”. https://surakarta.go.id/?page id=3132. Accessed : 20-09-21.

J. Pignataro, Louis, 1973, “Traffic Engineering Theory and Practice”, Prentice-Hall, inc. USA. 
Jurnal Matriks Teknik Sipil

DOI: https://dx.doi.org/10.20961/mateksi.v9i4.54779

ISSN: 2354-8630

E-ISSN: $2723-4223$

Vol. 9, No. 4 (2021): Desember

Putri, Nurjannah H., 2015, "Kalibrasi Vissim untuk Mikrosimulasi Arus Lalu Lintas Tercampur pada Simpang Bersinyal pada Simpang Tugu Yogyakarta", Universitas Gajah Mada. Yogyakarta.

Yulianto, B., \& Setiono., 2013, "Kalibrasi dan Validasi Mixed Traffic Vissim Model", Media Teknik Sipil, pp. 1-10.

Pemerintah Republik Indonesia, 2009, "Undang-Undang Republik Indonesia Nomor 22 Tahun 2009 tentang Lalu Lintas dan Angkutan Jalan”, Kementrian Riset, Teknologi, dan Pendidikan Tinggi, Jakarta. 